Disponível em

http://www.anpad.org.br/rac

RAC, Rio de Janeiro, v. 17, n. 4, art. 1,

pp. 398-417, Jul./Ago. 2013

$(\infty)$ EY-No

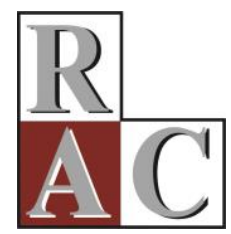

\title{
Mulheres e Suas Histórias: Razão, Sensibilidade e Subjetividade no Empreendedorismo Feminino
}

\author{
Women and Their Stories: Reason, Sensibility and Subjectivity in Women \\ Entrepreneurship
}

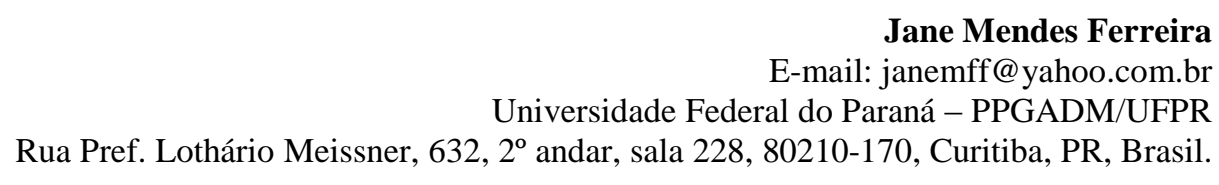

Eloy Eros Silva Nogueira

E-mail: esn.eros@gmail.com

Universidade Positivo - UP

Rua Prof. Pedro Viriato Parigot de Souza, 5300, Campo Comprido, 81280-330, Curitiba, PR, Brasil. 


\title{
Resumo
}

O objetivo deste artigo é identificar os elementos que permitem conhecer a subjetividade de mulheres empreendedoras segundo a teoria proposta por González Rey (2009). A subjetividade se dá por meio de uma configuração de sentidos subjetivos provenientes tanto do plano individual, como também dos construídos socialmente. Assim, a constituição subjetiva é formada por meio de diferentes forças que se mantêm em permanente transformação ao longo da trajetória dos sujeitos. A metodologia utilizada para alcançar o objetivo seguiu os parâmetros da Epistemologia Qualitativa. Trata-se de uma abordagem qualitativa em que é utilizado um conjunto de procedimentos específicos desenhados especialmente para desvendar os indicadores de sentido que, por sua vez, formam a configuração subjetiva. Os resultados indicam que a configuração subjetiva do empreendedorismo para as mulheres está apoiada em sentidos subjetivos associados às suas trajetórias, ao contexto atual e à cultura dentro da qual a atividade é desenvolvida. O empreendedorismo, nesta pesquisa, aparece como uma característica individual que começa a ser constituída na infância. No entanto, as empreendedoras se constituem como tal ao longo de sua história, quando devem lidar com as condições adversas do mundo empresarial, visto como machista. Nesse contexto, a abertura da empresa é um evento que marca fortemente a trajetória dessas mulheres, tendo uma natureza simbólica que atua como constituinte da subjetividade delas. No mesmo sentido, a multiplicidade de papéis e a concorrência entre espaços sociais, pois sublinham que a família interfere na dinâmica dos negócios, assim como os mesmos negócios estão presentes em seus lares. Além disso, a forma como empreendem é delimitada pelas condições concretas em que viveram/vivem.

Palavras-chave: subjetividade; empreendedorismo; mulheres empreendedoras.

\begin{abstract}
The purpose of this article is to identify the elements that allow understanding the subjectivity of women entrepreneurs according to González Rey's theory (2009). Subjectivity is a configuration of subjective senses originating from individual and social levels. Thus, a subjective constitution is formed by different forces that remain constantly changing throughout subjects' history. The methodology used to achieve the objective of this paper follows Qualitative Epistemology. This is a qualitative approach that uses a set of specific procedures specifically designed to reveal the indicators which form the subjective configuration. The results indicate that women's subjective entrepreneurship configuration rests on subjective meanings associated with the trajectories, context and culture within which the activity is developed. Entrepreneurship in this research appears as an individual characteristic that is formed in childhood. However, these women exist as entrepreneurs throughout their histories; especially when they have to deal with adverse conditions in the business world, which is seen as sexist. In this context, a company's opening is an event that strongly marks these women's histories, with a symbolic nature that becomes an integral part of their subjectivities. Similarly, the multiplicity of roles and competition between social spaces highlight how family interferes with business dynamics, as well as how businesses are present in the home. Also, the way they undertake entrepreneurial activities is delimited by the concrete conditions in which they lived / live.
\end{abstract}

Key words: subjectivity; entrepreneurship; entrepreneurial women. 


\section{Introdução}

Interessante dizer que a atuação da mulher no mundo dos negócios vem se consolidando no Brasil. O Global Entrepreneurship Monitor mostra que a participação das mulheres nas taxas de empreendedorismo nos últimos 10 anos manteve-se em torno de 49\% (Instituto Brasileiro de Qualidade e Produtividade [IBPQ], 2012). Esse dado per se seria suficiente para desencadear uma série de estudos tratando do tema. No entanto, "há pouco conhecimento sobre a atuação de empreendedoras no país" (Machado, Greatti, \& Jesus, 2010, p. 88).

A despeito da relevância da participação feminina, empreender para elas não tem sido uma tarefa fácil. Gimenez (2010) afirma que as mulheres enfrentam maiores empecilhos no acesso a fontes de financiamento e, muitas vezes, são discriminadas em processos sucessórios nas empresas familiares.

São poucas as pesquisas que se ocupam em desvelar as nuances que cercam o tema, especialmente tendo como pano de fundo a subjetividade. Uma evidência disso pode ser encontrada no trabalho de Silveira (2010). A autora analisou a produção científica do período de 2006 até 2008 em periódicos da base de dados do Social Sciences Citation, encontrando 179 artigos que tratavam de empreendedorismo, dos quais $0,74 \%$ tinham foco sobre o empreendedorismo feminino.

Nos periódicos nacionais em revistas como RAC, RAE, Cadernos Ebape, BAR, RAM, o percentual é de $2,7 \%$. A produção científica mais expressiva em termos quantitativos concentra-se em eventos como o Encontro sobre Empreendedorismo e Gestão de Pequenas Empresas (Egepe) e Encontro da Associação Nacional dos Cursos de Pós-Graduação e Pesquisa em Administração (EnAnpad). Nesses encontros, a temática gira entre 2 e 3 trabalhos por ano. Em outras palavras, ainda há espaço para discussão sobre o tema. A maior parte da produção científica se volta para a descrição de características associadas aos empreendedores de forma geral e, entre tais estudos, encontram-se aqueles que buscam definir as peculiaridades das mulheres frente aos negócios (Guimarães, 2004). Frente a esse contexto, os pesquisadores têm advogado que é necessário estudar o tema sob novos enfoques (Borba, Hoeltgebaum, \& Silveira, 2011; Silveira, 2010).

Por tais razões, propõe-se, nesta produção acadêmica, apresentar uma pesquisa sobre empreendedorismo feminino utilizando, como pano de fundo, a subjetividade em uma concepção sócio-histórica. O objetivo do artigo é identificar os elementos que permitem conhecer a subjetividade de mulheres empreendedoras, segundo a teoria proposta por González Rey (2009). É importante ressaltar a centralidade da Teoria de González Rey sobre os estudos acerca da subjetividade, tendo em vista que, na presente pesquisa, pretendeu-se aplicá-la para estudar a configuração subjetiva da mulher empreendedora. Mas essa opção de teoria substantiva demanda que também seja a própria teoria metodológica que fundamenta, esclarece e traça o caminho para que se possa conhecer tal subjetividade. Assim, apresentar os resultados dessa pesquisa requer a recuperação de alguns dos conceitos centrais dessa abordagem, coordenando aspectos substantivos e formais, destacando a singularidade como espaço privilegiado para a construção do conhecimento científico, pois no âmbito da Teoria da Subjetividade de González Rey, o indivíduo carrega em si elementos do todo.

Partindo da concepção sócio-histórica, admite-se que a atividade empreendedora permite a inserção do indivíduo no mundo de significados relativos aos negócios. Falar sobre a mulher empreendedora sob tal concepção é articular uma constituição social relacionada também com a história (Aguiar \& Ozzela, 2006). Assim, pode-se dizer que mulher empreendedora é, ao mesmo tempo, singular e histórica. Ela não é determinada pelas condições sociais e históricas, mas é capaz de elaborar sua subjetividade na geração de sentidos e significados em seus diferentes sistemas de relação. Diante disso, é possível dizer que a mulher empreendedora também pode transformar o contexto em que está inserida, tendo no diálogo um importante elemento nos processos de sua configuração subjetiva (González Rey, 2002). Em outras palavras, a mulher tanto constitui sua subjetividade a partir de elementos individuais como também a partir dos que lhe são passados pelas 
diversas vias da subjetividade social, mas que encontra nela um indivíduo reflexivo capaz de modificá-los, dando-lhes novos sentidos e constituindo-se a partir deles.

Para a consecução do objetivo desta produção acadêmica, além da presente introdução, são apresentados: o quadro teórico de referência, a metodologia, os caminhos pelos quais a informação foi construída e as conclusões.

\section{Quadro Teórico de Referência}

Respeitando as demais correntes de pensamento e suas contribuições, optou-se por olhar para o empreendedorismo feminino a partir de uma concepção sócio-histórica. Tal concepção possui suas raízes no trabalho de Lev Vygotski, que advogou por uma ciência marcada pela interdisciplinaridade. $\mathrm{O}$ seu argumento principal era de que o homem também cria e transforma o ambiente e, assim, pode fornecer novas formas de consciência. Para o pensador russo, o psiquismo possui uma natureza cultural e se desenvolve a partir da passagem do biológico para o simbólico. O homem é propenso para a experiência cultural para um devir ou vir a ser humano (Vygotski, 2009).

O trabalho de Vygotski é fundamento, por sua vez, da teoria da subjetividade de González Rey (2003, 2005), psicólogo cubano radicado no Brasil. Em coerência com o trabalho de Vygotsky, a subjetividade não é algo que possa ser apreendido em sua totalidade, pois não tem como pressuposto uma visão essencialista. Na teoria da subjetividade, o ser humano não possui uma natureza humana, mas se faz humano nos processos social, histórico e a partir de suas condições concretas. Subjetividade para González Rey (2009, p. 126) é:

Um sistema permanentemente em processo, mas com formas de organização que são difíceis de descrever e que, portanto, são epistemologicamente não acessíveis à descrição.... A subjetividade é da ordem do constituído, mas representa uma forma de constituição que, por sua vez, é permanentemente reconstituída pelas ações dos sujeitos dentro dos diversos cenários sociais em que atuam.

Como pesquisadores, o que se pode fazer é compreender como a subjetividade se processa naquele momento. González Rey (2003) esclarece que sua teoria é oposta ao estruturalismo porque este último representa a morte da subjetividade. Para ele, no estruturalismo, apesar de se partir da linguagem para explicar a estrutura, o sujeito está diluído no discurso.

A teoria de González Rey (2009) retoma o caráter dialético da constituição do sujeito. Para ele, é importante uma investigação que tenha como pano de fundo a teoria das configurações subjetivas, na qual tanto a subjetividade individual como o social sejam desvelados.

A subjetividade individual emerge da história das pessoas que estão, por sua vez, imersas em uma cultura. Paradoxalmente, a subjetividade social é formada pelos sentidos que caracterizam os espaços sociais dos indivíduos (Stangherlim, 2006). Para Dobránszky (2007), os conceitos de subjetividade individual e social são níveis diferentes de um mesmo processo. Para ele, a subjetivação não é feita de forma linear e imediata, mas acontece dentro de configurações subjetivas atuais do sujeito. Essa afirmação de Dobránszky parece resumir todos os trabalhos recentes de González Rey, nos quais se pode perceber que os diferentes espaços sociais em que o sujeito está inserido contribuem para a formação da subjetividade desses indivíduos, não os determinando, mas participando de sua formação.

Para González Rey $(2003,2005,2009$, 2010), essas duas fontes da configuração subjetiva estão em constante movimento. A subjetividade social perpassa a individual e está representada no contexto no qual se organiza a subjetividade individual. González Rey (2009) afirma que não se pode ignorar o caráter subjetivo dos processos sociais. Assim, o indivíduo não apenas reproduz as imposições do meio, mas é capaz de refletir sobre elas tornando-se sujeito da própria história ao elaborar tais 
imposições e criar o novo. Já a subjetividade individual se produz em espaços sociais constituídos historicamente.

O conceito de sentido subjetivo enfatiza a relação entre o simbólico e o emocional, e não apenas do intelectual e do afetivo. As configurações subjetivas surgem a partir de um sistema no qual diversos elementos presentes naquele momento podem, inclusive, ser contraditórios. O fenômeno subjetivo, como defendido por González Rey, não é interiorizado, ele se configura em um ambiente cultural.

Ao definir sentido de forma a dar coerência às suas proposições teóricas, González Rey (2010, p. 6) afirma que: "Quero me referir ao termo sentido subjetivo como unidade psicológica que expressa o caráter subjetivo dos processos psíquicos humanos nas condições de cultura". A caracterização do sentido envolve três condições-chave: (a) envolvimento com a subjetividade como sistema; (b) unidade com o simbólico e o emocional; (c) relacionamento com definição de espaços simbólicos. A inovação dessa concepção está em considerar o sentido como uma "complexa organização simbólicoemocional que está além da consciência e das representações atuais do sujeito. Sendo assim, o sentido subjetivo não é construído, mas produzido pelo sujeito" (Dobránszky, 2007, p. 32).

A apreensão dos sentidos revela expressões do sujeito que são, muitas vezes, contraditórias. $\mathrm{O}$ próprio sujeito pode desconhecer os sentidos, pois não os articulou ao não se apropriar da totalidade de suas vivências (Aguiar \& Ozzela, 2006). Reconhecendo a complexidade dos fenômenos humanos, Stangherlim (2006) conclui que:

gestos, pensamentos, atitudes, ações são exemplos desses fenômenos que são, por sua vez, responsáveis pela constituição de sentidos subjetivos produzidos por cada um de nós nas relações que estabelecemos em diferentes dimensões de nossa vida familiar, educacional, profissional e de lazer, por exemplo (p. 2).

Segundo González Rey (2010), a categoria sentido vai permitir uma aproximação do afetivo e do cognitivo. Ele ressalta, porém, que esta aproximação não significa fusão, tornando-os indiferenciados, nem tampouco que podem ser compreendidos separadamente, mas que há uma relação dialética entre esses elementos. Para González Rey (2010, p. 331), "é na relação que Vygotski estabelece entre o sentido e a personalidade que se abre uma importante perspectiva para nova definição de subjetividade".

Explicando melhor, o sentido subjetivo está na base da subjetividade individual e social, representando unidade e confrontação entre elas e configurando-se subjetivamente. Já os aspectos simbólicos e emocionais fazem parte de uma relação recursiva e não causal.

Além disso, os sentidos estão relacionados aos elementos produzidos pela cultura (como as condições de gênero) e também se constituem no plano individual por meio das emoções configuradas na história de cada sujeito ao se deparar com as representações sociais (González Rey, 2010).

As representações sociais não são descartadas por González Rey (2003), mas consideradas de forma peculiar. Ele parte do pressuposto que tais representações não fornecem simplesmente uma reprodução da realidade, mas são formadas tanto no âmbito individual quanto no social. $\mathrm{O}$ conhecimento da realidade não está desvinculado das intenções e valores dos sujeitos que nela estão inseridos. Com isso, concorda Bernardes (1998): os fenômenos psicológicos são construídos por meio de práticas sociais e históricas, fazendo com que sejam representados em acordo com o conhecimento que o sujeito produz a respeito dele.

O conceito de representações é importante para compreender a gênese e o desenvolvimento do conhecimento social, pois essa categoria permitiu "compreender o conhecimento social de natureza simbólica e social, que produz significações mais além de qualquer objeto concreto que apareça como conteúdo de uma representação" (González Rey, 2003, pp. 123-124). A representação da realidade é uma produção subjetiva que possui fundamento social, ou seja, não é apenas um reflexo dos objetos externos. 
A constituição dos indivíduos se dá na junção entre as forças sociais e a ação do sujeito. Dito de outra forma, o sujeito é produtor da realidade ao mesmo tempo em que reproduz as forças sociais (Severiano, 2007).

Em poucas palavras, o ser humano se constitui no social, mas os elementos que são a ele apresentados pelas diversas vias de subjetivação social são também subjetivados individualmente. No processo de produção humana, não há relação de causa e efeito (González Rey, 2010).

Quando se tem presente que a subjetividade é complexa e configurada por vias individuais e sociais, pode-se dizer que os diversos espaços sociais e simbólicos, tais como a atividade empreendedora e a condição de gênero, concorrem no processo de constituição da subjetividade. Isso porque o gênero de um indivíduo pode ser entendido como um espaço simbólico produzido pela cultura, alimentando-se das emoções particulares configuradas na história de cada sujeito. $\mathrm{O}$ empreendedorismo, por sua vez, pode ser considerado uma das zonas que fornecem sentidos subjetivos porque está presente em experiências sociais concretas que afetam a subjetividade individual, e os sujeitos, a partir dessas experiências, (re)constroem a subjetividade social.

Considerar gênero e empreendedorismo como produções também subjetivas, abrem-se possibilidades para escapar de dualismos e dicotomias. As questões de gênero e a atividade empreendedora não podem ser separadas de questões sociais e significações e ressignificações no plano individual. As representações sociais do que é ser mulher e empreendedora são colocadas para os indivíduos pelas diversas vias da subjetividade social, mas também são objeto de reflexão por parte do indivíduo.

Em síntese, pode-se registrar que tanto o ser mulher, quanto o ser empreendedora funcionam como produções sociais, configuradas a partir dos significados atribuídos pelo próprio indivíduo, que lhes confere sentido único.

\section{Metodologia}

Cumpre assinalar que, como se trata de uma teoria complexa, os métodos para empreender pesquisas desse tipo não podem estar alinhados àqueles que buscam relações de causa e efeito. Ciente dessa peculiaridade, González Rey propôs a epistemologia qualitativa. As características do método proposto pelo pensador cubano são:

- Papel ativo do pesquisador, sendo também considerado um sujeito da pesquisa.

. Sujeito e objeto de pesquisa estão implicados um no outro.

- Não há realidade última, mas zonas de sentido, pois o conhecimento é um processo em constante construção.

- O singular é espaço privilegiado para a construção do conhecimento científico, pois o indivíduo carrega em si elementos do todo.

- A validade da pesquisa está na capacidade do modelo teórico em ampliar as alternativas de inteligibilidade sobre o fenômeno estudado.

A valorização do caso singular para um processo de pesquisa é justificada por meio do entendimento do conhecimento como algo dinâmico que não fornece acesso ilimitado ao real, mas sim está em permanente construção, sendo elaborado por um pesquisador em constante atividade reflexiva e construtiva, estabelecendo zonas de sentido para o modelo teórico em construção, que não pode ser apoiado em uma noção de ciência que seja acumulativa e empírica. 
Para González Rey (2005), o novo modelo de ciência que valoriza o singular na pesquisa está intimamente ligado a uma opção epistemológica em que as pesquisas possuem validade científica, não pelo poder de generalização estatística, mas pela capacidade de gerar conhecimento a partir do singular. Em outras palavras, pela capacidade em ampliar as alternativas de inteligibilidade sobre o fenômeno estudado.

Ao empreender, em uma pesquisa que adote a Epistemologia Qualitativa de González Rey, a análise recai sobre os processos explicando os objetivos ao invés de descrevê-los. Nessa linha, a inteligibilidade da subjetividade das empreendedoras tem seu ponto de partida no empírico, mas não se esgota na descrição das práticas dessas mulheres. Ao invés disso, é necessário buscar a compreensão da constituição da subjetividade em seu processo histórico. Em outras palavras, é analisar o desenvolvimento e não as partes constituintes de um objeto de estudo. De forma mais concreta, o método não estabelece categorias fechadas e plenamente definidas, pois são consideradas como processos.

Os instrumentos de coleta de dados utilizados para alcançar o objetivo desta pesquisa foram: entrevista semiestruturada e complementos de frases.

A entrevista foi eleita como uma das técnicas de coleta de dados por ser adequada para capturar as complexidades da experiência e da percepção dos sujeitos analisados (Corbetta, 2003). O tipo de entrevista utilizado foi a semiestruturada.

O teste de complemento de frases foi utilizado como elemento auxiliar na coleta de dados. Isso foi feito para facilitar expressões do sujeito e permitir uma construção mais ampla dos sentidos subjetivos e dos processos simbólicos que constituem a sua configuração subjetiva. Trata-se de um instrumento recomendado por González Rey (2005), e caracteriza-se de proposição de início de uma frase (trechos chamados de indutores), complementada pelo respondente com aquilo que considera apropriado no momento. $\mathrm{O}$ instrumento coaduna-se com a pesquisa de cunho sócio-histórico porque parte-se do pressuposto de que o pensamento se concretiza na palavra (Vygotski, 2009).

A escolha dos instrumentos está ligada ao pressuposto de que, ao relatar a própria história, as empreendedoras tiveram a oportunidade de refletir sobre a atividade empreendedora e a própria vida. Isso porque a narração de si pode ser via privilegiada para o pensamento reflexivo.

A análise dos dados foi feita com a busca de indicadores de sentido subjetivo. Esta técnica é recomendada por vários pesquisadores que tratam do tema (Aguiar \& Ozzela, 2006; Dobránszky, 2007). Isso porque, no escopo da pesquisa sobre subjetividade, na perspectiva proposta por González Rey, a lógica configuracional é o processo que combina a indução e a dedução para trabalhar com duas realidades de distintas naturezas: a empírica e a proposição teórica. Essa lógica contribui nos processos intelectuais para se desenvolver o conhecimento sobre a subjetividade, e situa o pesquisador na orientação e no modo de produção das informações e elaboração de teorias.

O pesquisador, além dos dados obtidos de forma direta à experiência e obtidos como resultantes de sistemas de correlações, também labora com indicadores - "aqueles elementos que adquirem significação graças à sua interpretação" (González Rey, 2005, p. 112). O indicador como recurso metodológico é uma informação elaborada pelo pesquisador, que oferece direção e sentido no processo de produção de novas informações, categorias e inferências.

A definição do indicador é o passo que orienta o caminho de produção do conhecimento. Segundo González Rey (2005, pp. 114-115),

o indicador se torna elemento de relação entre diferentes níveis de produção teórica e as zonas de sentido do objeto a que os ditos níveis dão acesso.... O caminho das hipóteses que segue o curso ativo do pesquisador em face das múltiplas encruzilhadas do processo de pesquisa é acompanhado da produção de indicadores que facilitam a interação entre as ideias do pesquisador e as manifestações do estudado, por meio do qual avança em direção a construções mais abrangentes do processo de produção de conhecimento, as quais são de caráter temporário. 
Esta fase da pesquisa chama-se Construção da Informação e, por meio dela, procura-se legitimar o conhecimento a respeito do fenômeno estudado. A legitimação do modelo alcançado é processual. Não deve haver expectativa de alcance da essência do fenômeno estudado, mas de momentos de inteligibilidade sobre o empreendedorismo e a condição de ser mulher empreendedora.

Os sujeitos da presente pesquisa são três mulheres empreendedoras atuantes em Curitiba/PR. Essa quantidade pode ser justificada em função do tipo de teoria e dos pressupostos utilizados como sustentação da pesquisa, que não está centrada em uma ideia de ciência baseada em dados quantificáveis e suscetíveis à verificação imediata. Na teoria da subjetividade, o singular é validado como espaço privilegiado para a construção do conhecimento científico.

A escolha das depoentes se deu aleatoriamente. Os nomes das informantes da pesquisa foram alterados para resguardar suas identidades. A informante 1 será chamada de Maria, cuja transliteração do hebraico significa rebelião. A segunda será chamada de Ísis, cujo significado representa o espírito maternal. A informante 3 será aqui chamada de Emília, que significa ávida.

Procurou-se, ao longo da entrevista, dar possibilidade para que as mulheres manifestassem livremente seus desejos, emoções e experiências contidas na representação delas mesmas. Isso possibilitou a captação daquilo que Alves (1997) chamou de encruzilhada entre o individual e o social. Isso porque as configurações subjetivas são formadas pelos sentidos subjetivos, que, por sua vez, são constituídos individualmente, mas estão em constante interação com a subjetividade social. Espaços de produção simbólica podem ser encontrados na atividade empreendedora assim como em outras atividades nas quais as mulheres participam, passando a fazer parte da história delas.

\section{Construção da Informação}

Por meio da análise das histórias de mulheres proprietárias de empresas, procurou-se identificar o que era realidade para elas. Isso se deu por meio da palavra, uma vez que fornece os significados concebidos na interação do sujeito com a sociedade.

As entrevistas efetuadas não resultam em modelos de generalização estatística para a população de mulheres empreendedoras de Curitiba ou do Brasil. No entanto, a partir do pressuposto de que o indivíduo carrega em si elementos do todo, é possível pensar o fenômeno empreendedor por meio do relato dessas mulheres. $\mathrm{Na}$ análise, procurou-se elaborar uma síntese da biografia das respondentes, enfatizando os momentos em que as emoções, a atividade e as representações sociais afloravam reconstruídas pela memória. O relato delas foi feito à luz de suas representações atuais. Assim, mesmo ao falar de eventos do passado, tais eventos passaram pelos filtros atuais, com justificações do sistema de representações que elas possuem nos dias de hoje.

\section{Maria}

Maria é uma mulher de 60 anos que se engaja na atividade empreendedora como forma de suprir necessidades familiares que foram socialmente constituídas. Nasceu em uma cidade do interior do Paraná, à qual os ideais do movimento feminista chegaram com suavidade, fazendo com que ela se utilizasse de diversas estratégias para conseguir construir sua própria trajetória. Não se rebela totalmente contra o sistema, mas utiliza meios para desafiar o que lhe é dado como certo, mas que não lhe serve.

A partir de seu relato e do complemento de frases, sendo ainda apoiado na base teórica, o modelo conceitual da constituição subjetiva de Maria permite dizer que o empreendedorismo na trajetória dessa mulher, ao mesmo tempo em que concretiza o desafio de menina, também é limitado pelas representações sociais relativas ao papel de mulher. 
A trajetória de Maria não acontece isolada no tempo e no espaço. Está imersa em uma cultura que é (re)construída constantemente pelos indivíduos. A subjetividade social, ao encontrar em Maria um sujeito capaz de refletir sobre a própria condição, faz com que os elementos sejam por ela subjetivados de forma única. Assim, a representação do papel de mulher que lhe estava sendo passada não lhe servia. A subjetivação das experiências vividas por Maria levou-a a desafiar o papel tradicional que lhe era dado. Dessa forma, ela busca outro tipo de vida e vê, no trabalho e no estudo, a possibilidade de romper com as condições que lhe eram dadas. No entanto, isso não é uma tarefa fácil, porque algumas atividades eram negadas às mulheres de seu tempo, ou então estavam restritas a profissões, tais como a de professora.

A reivindicação de espaço no mercado de trabalho, também para Maria, deu-se não com naturalidade, mas com teimosia. $\mathrm{O}$ gênero, como um elemento constitutivo das relações sociais, privilegiava, naquele caso, o poder patriarcal, que foi desafiado. $O$ desvio de conduta, no entanto, não é radical, mas feito aos poucos, utilizando o poder de persuasão e limitado pelas representações sociais do que é ser mulher. Esse tipo de comportamento provoca pequenas fissuras nos modelos tradicionais, como afirma Mestre (2004), o que acaba por modificar as representações sociais.

É possível também destacar o indicador de sentido subjetivo necessidade. Ela se viu na obrigação de continuar. No início, com vendas de porta em porta. Depois, também, vê-se impelida pela necessidade de abrir a empresa.

"Essa necessidade é que o (nome do marido) estava desempregado, e eu tinha que ter meios de continuar mantendo minhas filhas com o mesmo padrão de vida que elas tinham antes. Com estudos e tudo. Então, eu continuei, me esforcei cada vez mais".

A necessidade relatada por Maria é de manutenção de padrão elevado de vida. Tal necessidade é socialmente constituída e subjetivada de maneira única por ela, motivando-a a empreender.

As relações familiares aparecem a todo o momento no relato dessa empreendedora. A mãe tem um papel importante quando identifica a si mesma e se atribui características que crê lhe sejam favoráveis ao empreender: corajosa, ousada, cuidadosa, criteriosa, exigente, educada, simpática e amiga. São todas características positivas. As ações frente aos negócios são feitas em um sentido de corroborar tais traços. Ao completar as frases ela afirma: "sou muito ousada para fazer as aquisições para as lojas, depois corro atrás para que tudo seja vendido". Ao atribuir peculiaridades que a identificam enquanto empreendedora, ela fornece a representação social sobre o empreendedorismo que está presente na sociedade e que foi por ela subjetivado. Isso pode ser evidência que o empreendedorismo é uma construção social que atribui ao indivíduo determinadas características supostamente responsáveis pelo sucesso nos negócios. No relato de Maria, ela se vê como principal personagem de seu empreendimento. Tudo gira em torno dela. Na percepção dela, o empreendedorismo é um fenômeno individual influenciado pelas características pessoais que são, por sua vez, formadas na infância.

As três filhas trabalham com ela atualmente, e representam o incentivo e a necessidade que a motivam a continuar a empreender. A filha mais velha aparece com maior frequência no relato de Maria.

"Nessa época, o (nome do marido) sempre me acompanhava bastante para me ajudar. Eu não tinha funcionários, trabalhava eu e a (nome da filha). No final de semana, eu lavava calçada. Então eu me esforcei muito pra que as coisas dessem certo. Não ter muitos gastos assim e poder ir crescendo também".

"A [a filha mais velha] sempre me ajudou. Inclusive quando eu vendia de porta em porta, ela sempre me ajudou e sempre gostou também. Além disso, ela via a minha necessidade de ter alguém. Ela me acompanha até hoje. Sempre me dá apoio em tudo o que eu preciso, ela está sempre à disposição. [nome das outras duas filhas] nunca gostaram muito. Me ajudavam, mas não gostavam. Faziam por necessidade também, porque viam que eu precisava de alguém. A [nome da filha do meio] sempre me ajudava depois do almoço, depois que saía do colégio. E a [filha mais nova] agora há pouco tempo começou a trabalhar comigo". 
Saliente-se ainda que a subjetividade de Maria é afetada pelas relações familiares, ao mesmo tempo em que influencia na constituição subjetiva daqueles que estão à sua volta.

Pode-se destacar também o uso do pronome possessivo meu/minha em todo relato de Maria. A posse fornece a motivação para empreender. Isso pode ser notado na frase: "precisava continuar a sustentar minhas filhas da maneira como elas estavam acostumadas". O sentimento de posse expresso por Maria se reflete em sua conduta ao intervir na carreira das filhas e na parceria nos negócios com o marido. Ela não demonstra um tipo de possessão em que predomina a confiança no outro - a confiança de que as filhas podem tomar conta da própria carreira, pois, para ela, sua intervenção é necessária a fim de garantir uma atividade de maior renda para as filhas.

Sua influência na escolha da carreira das filhas é evidente. A filha mais velha sempre esteve ao seu lado no empreendimento, mas as outras duas buscaram outras profissões. No entanto, não tiveram tempo suficiente para construir carreiras, pois a pressão da mãe para a entrada delas nos negócios parece que foi acentuada. Maria relata que as outras filhas foram trabalhar em suas áreas de formação, mas ganhavam muito pouco e não fazia sentido para ela que as filhas construíssem suas vidas profissionais fora da loja.

"Porque deu certo, eu acho que seria interessante. Às vezes, o [nome do marido] fala 'deixa as meninas trabalharem com o que elas querem. Fazer o que elas querem.' Eu falo: 'mas elas ganham tão pouco fora'.... Eu acho que quando você trabalha com a família, com a união da família, eu acho que tudo cresce mais. Na minha opinião, parece que fortalece mais os vínculos de negócios, fortalece mais a amizade da família. Acho que cresce mais, em minha opinião. Porque a gente está sempre junto, mais unido, troca ideia junto. Eu acho que cresce, a gente cresce junto. Acho que em todos os setores, a gente cresce".

Ela consegue que as filhas abandonem o projeto de carreira em detrimento do projeto comum à família elaborado por ela mesma. Isso não acontece quando se trata do marido, que é relatado como tendo uma percepção diferente da dela "ele pensa de uma maneira e eu penso de outra". A imposição de sua vontade não parece ser consciente, ela parece que instaura uma moral que é fundadora de sua subjetividade, das filhas e também do marido. Dito de outra forma, o fato de Maria ter feito as filhas abandonarem o projeto de carreira individual é tido como a coisa certa a ser feita. A justificativa é que é bom para elas e para a família. O marido, por pensar diferente (então errado), inclusive em relação à participação das filhas, não pode participar do empreendimento. Em nenhum momento, ela relata o que as filhas pensam ou a expressão da vontade delas.

Na configuração subjetiva de Maria, a porção mulher se insere na porção empreendedora que se expressa em suas diversas ações.

Ísis

Ísis é uma empreendedora de 44 anos que passa por um momento de transformação. Ela é filha de empreendedor, estudou para ser professora, trabalhou em banco e tornou-se mãe. Cuidou da filha durante cinco anos e, passados esses anos iniciais, resolveu, então, trabalhar na empresa em que o marido mantinha uma sociedade. Aprendeu e o incentivou a abrir outra empresa junto com ela. A organização que criou com o marido prosperou. A filha já é adulta, e Ísis se descobriu na atividade empreendedora. Teve sucesso financeiro, investiu suas emoções na empresa e agora se vê em um momento decisivo de sua trajetória empreendedora: vender a empresa.

A representação social que possui da mulher é naturalizada. Em outras palavras, ela acredita que as diferenças entre os gêneros são decorrentes de alguma característica inata que deixa mulheres e homens diferentes entre si. Isso é expresso quando ela fala que "mulher é assim", atribuindo a ela mesma peculiaridades supostamente femininas. Ela parece não se dar conta de que tais características foram passadas a ela a partir da subjetividade social. Apesar de ser um fenômeno social, tais características são subjetivadas de modo único, resultando em uma configuração que, para Ísis, tanto a iguala a diversas mulheres de seu tempo, como também a torna uma empreendedora única. Para ela: 
"Eu acho assim, que ser mulher para mim é algo maravilhoso. A mulher tem uma capacidade de administrar várias coisas ao mesmo tempo, ela tem um jeito meigo de fazer as coisas. A mulher para mim é algo maravilhoso.... Isso é coisa da mulher. A mulher se preocupa. A coisa tá pegando fogo e eu estou ali [na empresa]".

Ísis afirma que sempre teve desejo de ser dona de seu próprio negócio. As razões do desejo aparecem no instrumento de complemento de frases quando se olha a totalidade das respostas. Em várias questões aparece o elemento financeiro, que é o indicador de sentido subjetivo na configuração dessa empreendedora. $\mathrm{O}$ ganho financeiro para ela aparece como medida de sucesso. Inclusive escreve que a ambição dela como empreendedora é ter \$uce\$\$o.

Quando ela declara seu conceito do que é ser empreendedora, informa características dela mesma: não ter medo. A partir da representação social do que é um indivíduo empreendedor, ela constrói a sua própria identidade e suas ações são realizadas de forma a corroborar com essa característica. Dessa forma, a cada decisão a ser tomada, a coragem é a que deveria prevalecer. A coragem aliada à aquisição constante de conhecimento prático compõem a configuração subjetiva dessa mulher.

A emoção está constantemente presente na sua fala ao se referir à empresa. O processo de pensamento que ela utiliza para tomar decisões e para pensar os rumos da empresa não está de modo algum dissociado das suas necessidades e interesses pessoais. Ao decidir e agir na empresa no curso de suas emoções, ela aprende. Ou seja, não se pode pensar o aprendizado sem levar em consideração as emoções que perpassam tal processo.

No complemento de frases, ela acredita que a família sente admiração pela atividade que desempenha. O papel que desempenha para a família, aliado ao orgulho que sente ao desempenhar a atividade empreendedora, indica que isso interfere na sua subjetividade e passa a defini-la como sujeito.

As experiências diversas que emergiram da atividade empreendedora são articuladas e resultam em transformações na sua configuração subjetiva. Ao relatar sua trajetória que culmina nos dias atuais, a situação da empresa reflete-se na forma como ela relata agora a relação com o marido. No relato de trajetória conjunta, o marido aparece como um complemento importante de sua ação empreendedora: caminhando juntos na criação da empresa, ele lhe é motivo de orgulho. No início da entrevista, quando nomeia a empresa, explica que esta é ela e o marido. Com a estabilidade, a organização passa a ter vida própria, e a empreendedora se relaciona com a empresa como um filho e, como tal, é nele que investe suas emoções.

Evidencia-se que os espaços em que vivem não estão dissociados. Para a compreensão desses espaços, é relevante entender o significado da atividade empreendedora. Depois de 14 anos de empresa, crescimento e, finalmente, o sucesso financeiro alcançado, ela agora vê no marido uma ameaça. Ela relata que:

"E eu e o meu marido, nós temos um diferencial muito grande. Eu sou muito econômica.... Então dá esses atritos e a parte também de ter que separar a pessoa física e pessoa jurídica e ele mistura tudo. Então já tive muitas discussões. Muito atrito e ele acha que pode sair aí e comprar e depois só chegar para mim e dizer assim: 'Olha, eu quero 10 mil'. Então eu digo: 'não, não, não é assim'”.

A relação dela com a empresa é permeada por emoções que estão, por sua vez, conectadas com os diversos espaços de produção subjetiva, como o casamento. O emocional e o simbólico se expressam em uma relação recursiva nos sentidos subjetivos como processos sempre em desenvolvimento. Dessa forma, a questão financeira que lhe foi motivadora para a abertura da empresa é agora razão de atritos com o marido. Para ela, o marido é a representação da mistura das vidas pessoal e profissional, e que pode ser vista na afirmação: "Eu e o [nome do marido] estamos num atrito muito grande por causa da empresa. Não sei se a palavra certa é certa, mas é a ganância, sabe? É uma pena, mas isso acontece". 
Da mesma forma como a empresa impacta no casamento, o momento pelo qual ela e o marido estão passando tem reflexos na forma como lidam com a empresa. O período que vive atualmente é de transformações. A filha não requer mais cuidados, e a empresa, que sempre foi um elemento importante do casamento em função de ter sido o espaço de sentimentos e emoções, cresceu, prosperou e teve recentemente seu primeiro revés. O casamento que parece nunca ter sido objeto de reflexão, agora precisa ser encarado sem que tenham a filha ou a empresa como mediadores da relação. Então, Ísis secretamente deseja romper com a sociedade empresarial. Ela relata que seu momento de maior tensão atualmente é o fato de ser sócia do marido. Durante a entrevista, a relação com o marido é constantemente lembrada e ressentida.

Toda a trajetória e os elementos presentes nesse momento se articulam, resultando em uma nova configuração subjetiva. Surge daí uma mulher que sabe de seu potencial. O conhecimento, agora de si mesma, decorrente da atividade empreendedora, fornece a ela um sentido subjetivo em que a confiança em si é o elemento central.

\section{Emília}

Emília, 44 anos, advogada, quase engenheira, gosta de fazer várias coisas ao mesmo tempo e vê na atividade empreendedora um canal para sua hiperatividade. É mãe, provedora do lar e empresária bem sucedida. Tudo isso lhe dá sentimentos de realização e orgulho.

Emília relata que exercia atividades profissionais desde cedo e não se referiu a nenhum tipo de proibição dos pais. Ela teve filho fora do casamento, morou sozinha e hoje mantém união estável, coisas que pareciam impensáveis para mulheres da geração de Maria, que nasceu e foi criada no interior do Paraná.

Ser mulher significa responsabilidade que não pode ser transferida a outros. No complemento de frases, a junção de algumas delas pode dar indicação dos elementos que compõem o sentido subjetivo de gênero para esta mulher:

"Ser mulher significa não ter opção de não assumir responsabilidades".

"Eu gostaria de poder falar que faça você mesmo".

"Eu secretamente gostaria de, às vezes, não me importar".

A palavra responsabilidade pode significar ônus, carga ou dolo. Na fala de Emília, esse sentido de ônus pode ser também evidenciado quando ela diz que, em algumas ocasiões, gostaria de passar um pouco de responsabilidade para os outros e ainda, secretamente, ela queria não se importar. No entanto, a responsabilidade e o peso de ser mulher estão presentes, e é ela quem assume tudo.

Apesar de o empreendedorismo ser considerado pela sociedade como uma característica individual que é transmitida aos filhos por pais empreendedores, quando se olha para a experiência de Emília, percebe-se que o comportamento do pai é subjetivado de modo único, resultando não na conformidade ao padrão, mas no desafio. O pai dela acha a atividade empreendedora muito arriscada, e preferiria que os filhos fossem também funcionários públicos em função da garantia de uma aposentadoria tranquila.

A empresa de Emília foi aberta em função da aceitação de oferta de um investidor que viu no negócio de fabricação de cozinhas planejadas uma oportunidade. Ela justifica a atividade empreendedora como um resultado de sua ânsia por fazer várias coisas ao mesmo tempo.

Ela acredita que possui capacidade para aprender e extrair do aprendizado algo útil. A segurança baseada na crença em sua própria capacidade é elemento que compõe a configuração subjetiva de Emília. Ela se considera capaz e suas ações são direcionadas de modo a corroborar esse comportamento (morar sozinha, não terminar o curso de engenharia, abrir a empresa, entre outros). 
Emília relata que a lógica é uma característica que, em sua opinião, ajuda na tomada de decisão a respeito de negócios.

"Eu sou uma pessoa extremamente lógica. Extremamente lógica. E número é número. Então você tem que me provar.... As minhas decisões são extremamente lógicas, por isso dificilmente a pessoa consegue [convencê-la]. Primeiro que eu não gosto. Dificilmente alguém consegue tirar essa decisão, porque ela é muito lógica".

A subjetividade social sobre o empreendedorismo aparece delineando o fenômeno como sendo um espaço simbólico ligado à racionalidade. A emoção não tem espaço no ambiente de trabalho para ela, somente a lógica e a razão. As relações emocionais são deixadas para outro espaço de constituição subjetiva, e aqui substituídas por relações de negócios, lógicas e racionais. Palavras estas que se juntam para formar um indicador de sentido subjetivo que compõe a configuração presente no ser empreendedora.

As relações familiares atuais aparecem pouco no relato de Emília. Ela parece valorizar a separação dos espaços de casa e trabalho, ao menos conscientemente. Mas, quando se olha para as ações efetivas, ou seja, a contratação do marido com uma descrição de cargo bem específica:

“Então eu precisava de alguém de confiança pra fazer isso, daí veio o meu marido pra cá. Então hoje o meu marido é funcionário aqui. Ele fica com o administrativo financeiro, mas o administrativo financeiro operacional, não é o administrativo financeiro".

Mesmo em relação aos filhos, ela não espera, ou melhor, não quer que trabalhem com ela:

"Eu já falei para os meus filhos que eles têm o melhor estudo que eu posso dar. O melhor que eles podem ter, o problema é deles. Depois dos dezoito, dezenove, eu não tenho que deixar nada pra eles. Eles tiveram toda condição pra ir pra frente. Vão fazer a vida deles”.

Todas essas experiências foram subjetivadas e compõem a configuração subjetiva de gênero para essa empreendedora em que prevalecem os sentidos de dever, controle e racionalidade.

Como explicado anteriormente, esta pesquisa foi desenvolvida utilizando complementos de frases e de entrevistas reflexivas, dotadas de foco, mas abertas e pautadas pelo diálogo e pela espontaneidade. Esse contato permitiu, além da obtenção das respostas, observar gestos, atitudes, mensagens e símbolos, subsidiar a reflexão diária, presenciar e colher testemunhos e depoimentos pessoais, revelando detalhes biográficos e visões de mundo, das situações e de si.

Desse processo, alguns indicadores surgiram e foram considerados relevantes no processo de análise e construção da informação.

Observou-se que, para essas entrevistadas, o espaço social para as atividades de empreender, mais do que a área física da empresa, é o próprio empreendimento, compreendido como o espaço simbólico em que são construídos e confirmam o sentido subjetivo de ser mulher empreendedora.

Por exemplo, na análise, foram identificados os sentidos de iniciativa e o de autonomia. Para González Rey, os sentidos permitem conhecer a relação dialética entre afetivo e cognitivo. Eles são complexas organizações simbólico-emocionais subjacentes à própria consciência, cujas ideias, atitudes e ações por ela produzidas nas relações com o empreendimento são responsáveis pela constituição dos sentidos subjetivos.

Em seus depoimentos e atitudes, as entrevistadas transmitem uma imagem de condutoras líderes do conjunto de atividades empreendedoras, e ainda a de ser quem decide. A imagem que fazem de si mesmas é a de pessoa decidida. Trata-se de um sentido de capacidade específica: de serem capazes descrita, confirmada, traduzida e identificada em suas afirmações - de: enfrentamento de riscos e incertezas dos negócios, de terem de fazer escolhas, de lidar com a concorrência de responsabilidades e papéis, e outras situações. 
As atividades e as emoções combinadas a esses sentidos contribuem para a vivência desses espaços identificados como empreendedorismo. Na verdade, são elementos constituintes da subjetividade ao permitirem que o indivíduo seja sujeito da sua própria história. Essas inferências vêm ao encontro da argumentação de González Rey porque demonstra a relação entre sentido e significado, olhando as dimensões simbólica, cognitiva e emocional, para se compreender a subjetividade individual e a social.

Quando se olha para a entrevistada Maria, pode-se ver que exigência, desafio e esforço, agora já subjetivados, estão presentes na trajetória profissional como docente que foi, marcada por diversas funções assumidas pela competência demonstrada: professora, secretária e diretora. As atividades laborais são assinaladas por elogios à sua capacidade de fazer bem feito, o que reforça também o orgulho como indicador de sentidos subjetivos.

"Eu trabalhei no banco, nessa empresa, depois trabalhei como professora. Aí fui professora, fui secretária, fui diretora de escola e sempre fui bastante elogiada no que eu fazia e procurava sempre fazer o melhor.... Eu sempre gostei de fazer uma coisa bem feita, então tudo o que eu fiz realmente eu fui crescendo dentro do meu serviço".

"As pessoas sempre elogiam bastante o meu trabalho e desempenho das minhas lojas".

Ser mulher para Maria exige comportamentos específicos, que tem relação com a perfeição. A exigência que lhe foi cobrada, agora subjetivada, é também elemento que constitui sua ação como empreendedora, representando um desafio que somente pode ser vencido por meio de esforço. A porção mulher se insere na porção empreendedora, formando uma configuração específica que se expressa em suas diversas ações.

Sentido subjetivo semelhante surge no relato de Ísis. Em várias ocasiões, ela informa que sente orgulho por ter criado a empresa e prosperado, por seus funcionários aprovarem a maneira como os trata, e, ainda, pela família tê-la em grande consideração em função de ter empreendido e vencido. Enfim, a atividade empreendedora representa para ela uma forma de realização que se concretiza na forma de orgulho.

"Eu sinto orgulho. Tem um mezanino no fábrica e eu fico olhando e penso: Nossa! Para quem começou do nada".

O indicador de sentido subjetivo de orgulho aparece também na relação com os parentes fora de seu círculo restrito (marido e filha). A ação empreendedora dela também afeta a subjetividade de outros indivíduos.

"Hoje eu sinto que eu sou uma referência para minha família: para meu pai, para minhas irmãs. Até agora, não faz muito tempo, a minha irmã me disse: - Nossa, Ísis, tu és uma mulher empreendedora. Tu és uma pessoa, uma mulher de sucesso. Achei tão bonito ela dizer aquilo, sabe? Então, para família, hoje, eu sinto que a minha opinião tem um peso a mais".

Já a entrevistada Emília considera-se uma mulher diferente, pertencente a um grupo específico - mulheres de sucesso. Não são todas as mulheres que pertencem a essa confraria, apenas aquelas que desfrutam de sucesso profissional, como ela própria. Elas falam a mesma língua e, por isso, compreendem uma à outra.

"Por exemplo, todas as clientes mulheres que têm dinheiro, normalmente elas são minhas clientes. Quando a decisão é feminina, normalmente ela acaba virando minha cliente, não do meu sócio, mesmo que ela tenha entrado por ele. Até porque a comunicação é mais fácil. Quem sabe por ela ser uma empreendedora, ela entender, tipo assim, quando você fala que não dá, não dá, ela sabe que no negócio dela também tem coisa que não dá pra ser feita. E o primeiro impacto comigo é complicado, porque como eu falo alto, eu falo rápido, eu digo: 'Não dá pra fazer, não tem como fazer nesse prazo'. A pessoa às vezes fica assim, mas depois com o tempo ela percebe que eu digo: 'não dá pra fazer, mas vamos tentar fazer assim', porque se eu falar que vai fazer, vai fazer. Então, no final, meus clientes voltam sempre pra mim. Eu acho que é um relacionamento... Depois que aprende, porque a primeira vez, no telefone, assim, quando cai de paraquedas no meu colo, nunca dá certo". 
O sentido subjetivo de gênero, ao mesmo tempo em que é configurado pela responsabilidade, é também motivo de orgulho quando se alcança sucesso profissional. A definição do espaço simbólico de gênero, a produção cultural, além das emoções particulares, como nesse caso o orgulho de pertencer a uma classe especial (mulheres de sucesso), estão configurados na história de Emília. Em outras palavras, a configuração de gênero, além da concretude de sua vivência sempre integrada a processos emocionais, está ligada às ações do sujeito - o falar a mesma língua, reconhecer-se no outro, e ao ter o ônus por tudo que acontece à sua volta.

Essas elaborações analíticas parecem consistentes com as proposições de González Rey. A sua ideia de sujeito, e que não se encontra nas diversas correntes e teorias analisadas, é um sujeito que está:

de forma permanente, constituído por configurações subjetivas que não conscientiza. Ao mesmo tempo está produzindo de forma consciente um conjunto de projetos, reflexões e representações com capacidade de subjetivação, as quais são fontes de significado e sentido cujas consequências em torno do desenvolvimento de sua subjetividade estão mais além de suas intenções e de sua consciência, mas que passam a ser agentes importantes do desenvolvimento e das transformações produzidos desde sua atividade consciente (González-Rey, 2003, p. 50).

O fenômeno subjetivo defendido por González Rey não é interiorizado, mas se configura em um ambiente cultural não físico. Nesse sentido, a subjetividade, ao se mostrar nas representações sociais e nos diferentes espaços da vida do indivíduo, pode ser considerada uma categoria essencial para a compreensão da atividade empreendedora.

Nesse aspecto, parece residir a potencialidade dessa abordagem. Ao pensar a subjetividade como uma configuração de sentidos dados pelo sujeito naquele momento, ela busca ultrapassar o nível puramente descritivo das falas dos sujeitos para revelar os sentidos subjetivos que se configuram em suas experiências e nos diversos espaços sociais em que se encontram. Dessa forma, pode-se pensar em sentidos subjetivos de ser atleta, de ser mulher, de ser mulher de negócios, entre outros espaços, nos quais os indivíduos estão inseridos e desenvolvem suas subjetividades.

Ao longo do processo de pesquisa, constatou-se o que previam Aguiar e Ozzela (2006): as entrevistadas ofereceram algumas expressões contraditórias e outras que sugeriram conflitos. E elas ainda demonstraram desconhecer os sentidos ínsitos em serem mulheres empreendedoras, pois não os haviam articulado na apropriação da totalidade de suas vivências. À medida que se desenrolavam o encontro e as reflexões, elas indicavam estarem elaborando e revendo suas próprias experiências, e encontrando oportunidade de as sintetizarem em seus depoimentos e expressões.

O caráter mercantil do empreendimento tem impacto significativo na composição do espaço e da subjetividade social. E o fato da efetivação desse propósito mercantil depender da coordenação de vários empregados e atividades, inclusive de vendas, exige uma correspondência da configuração da subjetividade das entrevistadas, uma vez que se posicionam como dirigentes. Essa percepção parece recuperar a proposição de Dobránszky e González Rey (2006), de que compreender as produções dos sentidos subjetivos e como se organizam os processos de comunicação em uma equipe, são relevantes para se compreender as configurações subjetivas, tanto da subjetividade grupal, como de cada um dos participantes dessa equipe.

Por outro lado, as representações sociais dessas entrevistadas sobre ser mulher empreendedora convergem para as conclusões de Menezes e Bertucci (2009) e de Cramer, Cappelle, Silva e Brito (2001, 2012): (a) de que ela vive um cenário de conquista de espaço e necessita estar sempre provando que é capaz de gerir com sucesso seu empreendimento para ver reconhecidos seu espaço e identidade de empreendedora; (b) a socialização da infância exerceu grande influência sobre seu sistema de representação. É interessante que as entrevistadas não trouxeram qualquer indicação que a formação escolar tivesse desempenhado papel influente e causativo em sua escolha, inserção e trajetória de sucesso no mundo dos negócios e do empreendedorismo. 
Mas esse sucesso, semelhante ao que Machado, Silveira, Hoeltgebaum e Gouveia (2008) verificaram em sua pesquisa, não traz uma delimitação clara entre os aspectos pessoais e gerenciais. Isso sugere que os sentidos e significados a esse respeito estão imbricados entre si, refletindo-se na visão que têm dos espaços simbólicos e na multiplicidade de papéis, que são: o lar, o empreendimento, a empresa e as relações com os pares no ambiente empresarial. Os dados colocam em destaque a relação entre os espaços sociais que parecem concorrer entre si: o lar e o empreendimento. E, nessa relação, o tempo surge como o principal tema que pode ser associado a dificuldades e conflitos, similar às inferências de Zampier, Takahashi e Teixeira (2010).

Todos os elementos presentes na história das mulheres que compuseram a pesquisa são subjetivados de maneira única. Dessa forma, para entender a entrada no mundo dos negócios, não se pode desprezar as histórias dos empreendedores, embora não se possa também fazer afirmações do tipo: uma infância difícil leva a empreender ou pais empreendedores têm filhos empreendedores.

Como remate, é importante frisar que, a partir da representação social do que é um indivíduo empreendedor, elas constroem suas identidades e suas ações são realizadas de forma a corroborar essa característica. Cada uma delas entende o empreendedorismo a partir das próprias características individuais, da sua própria história e das representações sociais sobre indivíduos empreendedores significativos (superação, racionalidade, realização e orgulho).

\section{Considerações Finais}

Inicialmente, é importante ressaltar que, em todos os relatos das empreendedoras entrevistadas, a abertura da empresa marca com tamanha força suas trajetórias, o que não pode ser negado como constituinte de suas subjetividades. Dessa maneira, percebe-se que o empreendedorismo se insere na vida das pessoas fazendo parte delas, não podendo ser pensado como um fenômeno com existência própria.

Apesar de ser um fenômeno criado na cultura, transmitido pelas diversas vias da subjetividade social e, portanto, sofrendo influência do sistema econômico adotado no Brasil, o empreendedorismo aparece como uma característica que é constituída na infância e pertence somente a um indivíduo. Em outras palavras, apesar de que quando uma empresa é iniciada, em geral isso é feito com empenho de muitas pessoas, o empreendedorismo é visto como ação de um indivíduo que possui características específicas, que acaba por ser considerado o único responsável pelo sucesso nos negócios.

É fundamental mencionar que o empreendedorismo foi subjetivado por todas as mulheres como um fenômeno individual, como algo que possui conexão estrita com o indivíduo. Elas relatam características pessoais quando perguntadas sobre o que é ser empreendedor. Essa tendência individualista é também reflexo da sociedade competitiva e individualista em que se vive no momento.

Por meios dos relatos, percebeu-se que o fenômeno é perpassado pela vida e, por conseguinte, pelas transformações que ocorrem na vida dos sujeitos. Da mesma forma com que o empreendedorismo é afetado pela trajetória de vida dos indivíduos, ele afeta sobremaneira a vida da empreendedora e sua dinâmica familiar. Dito de outra forma, a família interfere na dinâmica dos negócios, assim como os negócios estão presentes na casa dos empreendedores. Algumas com maior ênfase, como no caso de Ísis, outras com o isolamento dos familiares para que não "atrapalhem" o andamento dos negócios. Os problemas da empresa vão para casa, assim como os problemas de relacionamento aparecem no cotidiano da organização. Por outro lado, as empreendedoras também se transformam no processo ao subjetivar as experiências da empresa interferindo em seu lar e viceversa. Isso tem implicações sobre a longevidade de empresas de pequeno porte, e também pode atuar como um elemento de restrição do crescimento de tais empresas.

A configuração das mulheres, produto dos sentidos subjetivos, não representa uma organização subjetiva universal e padronizada. O sentido subjetivo da atividade empreendedora é distinto em cada 
mulher. Cada trajetória confere um caráter totalmente singular à atividade desenvolvida por elas. Não há que se falar em característica de mulheres empreendedoras, porque isso iria contra o pressuposto adotado aqui de que o homem não traz dentro de si, ao nascer, uma essência que o destinaria a certa atividade (a empreendedora, por exemplo). Ao invés disso, cada empreendedora pode ser considerada uma complexa síntese em que a universalidade se concretiza social e historicamente por meio da atividade empreendedora que, por sua vez, é uma atividade social.

As trajetórias de vida das mulheres investigadas foram ímpares, mas acontecem sob um mesmo tempo e local. Assim, elas empreendem em uma sociedade que, apesar das lutas de tantas mulheres por maior igualdade de gênero, teve na industrialização o grande impulsionador senão da igualdade, pelo menos de maiores opções para elas (Rago, 2003). Então, a forma como elas empreendem é marcada por um tempo específico e local determinado. Elas são mulheres e empreendem no século XXI, no Brasil. Isso influencia a atividade desenvolvida.

As representações sociais sobre o que é o empreendedorismo e o que é ser uma mulher empreendedora não se impõem de forma absoluta, pois encontram um indivíduo capaz de refletir e formular teorias próprias a partir das quais elas justificam suas ações no cotidiano. A maneira por meio da qual elas sustentam a atividade empreendedora foi sendo incorporada e, ao mesmo tempo, delimitada pelas condições concretas em que viveram/vivem. A subjetivação acontece mesmo sem que essas empreendedoras se deem conta disso.

O empreendedorismo não tem por trás uma série de motivos específicos e universais. Assim, não há como se falar em abertura de empresas por necessidade ou por oportunidade e delimitar tais conceitos. Cada necessidade, apesar de ser constituída no social, é subjetivada individualmente, resultando em motivos que se organizam de forma única no contexto do empreendedorismo, fazendo parte de um processo de produção de sentido. No caso de Maria, ela relata que abriu a empresa por necessidade. No entanto, tal necessidade não guarda identidade com a necessidade de todos os empreendedores.

A emoção aparece em todos os depoimentos, mesmo Emília, que se diz absolutamente racional, procura isolar o marido das decisões, para que ela não tenha que lidar com as emoções que isso ocasionaria. A emoção está na base dos processos de pensamento. Portanto, não há que se pensar em empreendedorismo como um fenômeno do mundo dos negócios sem que a emoção seja levada em consideração. A empresa, como resultado de uma série de decisões em seus diversos níveis hierárquicos, está permeada de emoções. Isso porque o estado emocional do sujeito é fundamento de suas ações. Ao admitir isso e ao conhecer o tipo de emoção que está na base dos processos de pensamento, pode-se entender melhor o empreendimento e suas limitações. Admitir a emoção como participante do mundo empresarial pode dar ao indivíduo a oportunidade de conhecer a si mesmo e emancipá-lo.

Pode-se também afirmar que as empreendedoras posicionam-se ativamente frente às situações relativas aos negócios. Elas enfrentam as situações mesmo diante de sentimentos de insegurança. González Rey (2010) afirma que um posicionamento ativo frente à vida pode permitir criar sistemas de apoio para situações difíceis, fazendo com que os sujeitos desenvolvam uma identidade a partir dessa situação.

As questões de gênero também podem ser consideradas como construções sociais e espaço simbólico produzido pela cultura. Tais questões se nutrem das emoções particulares configuradas na história de cada sujeito. O indivíduo nasce com uma constituição biológica para ver, falar e agir, mas é na relação com o outro que vai perceber, comunicar-se e desempenhar atividades que, por um lado, reforçam e, por outro, desafiam o que está destinado a ele pela sociedade. Os padrões que estão disponíveis na sociedade são transmitidos culturalmente, mas são subjetivados de maneira única pelo indivíduo.

A partir do relato das mulheres, percebe-se que o que prevalece, ainda, na sociedade brasileira, é uma visão naturalizada dos gêneros. As pessoas ainda pensam que ser mulher é uma condição 
biológica e não social. Em todos os relatos, elas se referiam à mulher como tendo características específicas - peculiares do ser mulher - um ônus a ser carregado. No entanto, em todas as trajetórias investigadas, o que se pode perceber é que as mulheres envolvidas não estavam engajadas em fazer gênero de forma consciente. Não estão ocupadas em perpetuar ou não as diferenças entre os sexos. As mulheres empreendedoras desta pesquisa estão constantemente se firmando como sujeitos de sua própria história.

Pode-se entender, nessa linha, que a forma correta de ser mulher e empreendedora foi forjada no social. No entanto, o fenômeno somente pode ser entendido a partir do caráter ativo e constituinte das mulheres que fazem gênero e que são empreendedoras. Não significa, no entanto, que elas sejam apenas produto do meio, pois são produtos da cultura e também constituem a cultura no processo de desenvolvimento. A atividade empreendedora que elas desempenham e as representações sociais que a sociedade lhes impõe por meio das diversas vias da subjetividade social são configuradas subjetivamente.

Todavia, a empreendedora não expressa somente sua condição de mulher de negócios, mas sua condição social. A configuração subjetiva do empreendedorismo para as mulheres está apoiada em sentidos subjetivos associados às suas trajetórias, ao contexto atual e à cultura dentro da qual a atividade é desenvolvida. Dessa forma, todos os aspectos se conectam de maneira única na formação da subjetividade dessas mulheres.

Os elementos que surgiram como indicadores de sentido subjetivo formaram uma configuração única para cada uma das mulheres que fizeram parte da pesquisa. Tal dado permite afirmar que os elementos que compõem a configuração, apesar de serem socialmente constituídos, são subjetivados de maneira singular. Cada uma delas, de modo único, é parte de um fenômeno social sem que se deem conta disso, ou mesmo sem que estejam preocupadas com isso. Ao viver e agir de forma empreendedora constroem suas identidades, quebram alguns padrões e reforçam outros. Já ao viverem suas vidas, constituem-se sujeitos da própria história. Com suas trajetórias singulares e forma específica de apreender a realidade, elas deram origem a sentidos subjetivos particulares, apesar das palavras que expressaram significados generalizados.

Por fim, cumpre dizer que a teoria da subjetividade de González Rey pode ser uma opção para entender a subjetividade dos indivíduos em diversos espaços sociais. Trabalhos futuros tratando da subjetividade de mulheres no meio acadêmico, como estudantes de Administração e professoras, também parecem ser uma opção para melhorar o uso da teoria e alcançar maiores zonas de inteligibilidade sobre questões de gênero na área de Ciências Sociais Aplicadas.

\section{Referências}

Aguiar, W. M., \& Ozzela, S. (2006). Núcleos de significação como instrumento para apreensão da constituição dos sentidos. Psicologia Ciência e Profissão, 26(2), 222-245.

Alves, C. P. (1997). "Eu nunca vou para de buscar nada": emancipação frente à colonização e as políticas de identidade na adolescência (Tese de doutorado). Pontifícia Universidade Católica de São Paulo, São Paulo, SP, Brasil.

Bernardes, J. S. (1998). História. In M. G. Jacques, M. G., Strey, M. N., Bernardes, N. M. G., Guareschi, P, A., Carlos, S. A., \& Fonseca, T. M. G., Psicologia social contemporânea (pp.1935). Petrópolis: Vozes.

Borba, M. L., Hoeltgebaum, M., \& Silveira, A. (2011). A produção científica em empreendedorismo: análise do Academy of Management Meeting 1954-2005. Revista de Administração Mackenzie, 12(2), 169-206. doi: 10.1590/S1678-69712011000200008 
Corbetta, P. (2003). Social reasearch: theory, methods and techniques (B. Patrick, Trad.). London: Sage. (Obra original publicada em 2003)

Cramer, L., Cappelle, M. C. A., Silva, A. L., \& Brito, M. J. (2001). Representações femininas da ação empreendedora: uma análise da trajetória das mulheres no mundo dos negócios. Anais do Encontro de Estudos em Empreendedorismo e Gestão de Pequenas Empresas, Londrina, PR, Brasil, 2.

Cramer, L., Cappelle, M. C. A., Silva, A. L., \& Brito, M. J. (2012). Representações femininas da ação empreendedora: uma análise da trajetória das mulheres no mundo dos negócios. Revista de Empreendedorismo e Gestão de Pequenas Empresas, 1(1), 53-71.

Dobránszky, I. A. (2007). Subjetividade no esporte: o impacto da subjetividade do técnico na constituição de uma equipe de triatlo (Tese de doutorado). Pontifícia Universidade Católica, Campinas, SP, Brasil

Dobránszky, I. A., \& González Rey, F. L. (2006). Produção de sentidos subjetivos do técnico sobre o esporte. Anais do Congresso de Ciências do Desporto e Educação Física dos Países de Língua Portuguesa, São Paulo, SP, Brasil, 11.

Gimenez, F. A. P. (2010). Trajetórias empresariais femininas: estudo comparativo entre empreendedoras e sucessoras de empresas familiares (Projeto de Pesquisa CNPQ). Curitiba, PR, Brasil.

González Rey, F. L. (2002). O enfoque histórico-cultural e seu sentido para a psicologia clínica: uma reflexão. In A. M. Bock, M. D. Gonçalves, \& O. Furtado (Orgs.), Psicologia sócio-histórica: uma perspectiva crítica em Psicologia (2a ed., pp. 193-214). São Paulo: Cortez.

González Rey, F. L. (2003). Sujeito e subjetividade (R. S. Guzzo, Trad.) São Paulo: Pioneira Thomson Learning. (Obra original publicada em 2003)

González Rey, F. L. (2005). Pesquisa qualitativa e subjetividade: os processos de construção da informação (M. A. Silva, Trad.). São Paulo: Pioneira Thomson Learning. (Obra original publicada em 2005)

González Rey, F. L. (2009). O social na psicologia e a psicologia no social: a emergência do sujeito (2a ed., V. L. Joscelyne, Trad.). Petrópolis: Vozes. (Obra original publicada em 2004)

González Rey, F. L. (2010). As configurações subjetivas do câncer: um estudo de casos em uma perspectiva construtivo-interpretativa. Psicologia: ciência e profissão, 30(2), 328-345. doi: 10.1590/S1414-98932010000200009

Guimarães, T. B. (2004, setembro). Análise epistemológica do campo do empreendedorismo. Anais do Encontro Nacional da Associação Nacional de Pós-Graduação e Pesquisa em Administração, Curitiba, PR, Brasil, 27.

Instituto Brasileiro de Qualidade e Produtividade. (2012). Global entrepreneurship monitor: empreendedorismo no Brasil. Curitiba, PR, Brasil. Recuperado de http://www.ibqp.org.br/img/projetos/downloads/arquivo_20130502114043.pdf

Machado, H. V., Greatti, L., \& Jesus, M. J. (2010). Compreendendo a imersão de empreendedoras em redes: a institucionalização da Associação de Mulheres de Negócios de Maringá. In F. A. Gimenez, J. M. Ferreira, \& S. C. Ramos (Orgs.), Empreendedorismo e estratégia de empresas de pequeno porte - 3Es2Ps (Vol.1, pp. 88-108). Curitiba: Editora Champagnat.

Machado, H. V., Silvera, A., Hoeltgebaum, M., \& Gouvea, A. B. C. T. (2008, setembro). Significados de sucesso e fracasso nos negócios: o que dizem mulheres empreendedoras. Anais do Encontro 
Nacional da Associação Nacional de Pós-Graduação e Pesquisa em Administração, Rio de Janeiro, RJ, Brasil, 32.

Menezes, R. S., \& Bertucci, J. L. (2009, setembro). "Mulher de negócios": uma análise da representação social em base no discurso de empresárias associadas à Business Professional Women. Anais do Encontro Nacional da Associação Nacional de Pós-Graduação e Pesquisa em Administração, São Paulo, SP, Brasil, 33.

Mestre, M. B. A. (2004). Mulheres do século XX: memórias de trajetórias de vida, suas representações (1936-2000) (Tese de doutorado). Setor de Ciências Humanas, Letras e Artes, Universidade Federal do Paraná, Curitiba, PR, Brasil.

Rago, M. (2003). Os feminismos no Brasil: dos "anos de chumbo" à era global. Revista Labrys de Estudos Feministas, (3), 1-12.

Severiano, H. C. (2007). As confugurações do gênero na subjetividade: um olhar sócio-histórico sobre os papéis sexuais (Monografia de Graduação). Faculdade de Ciências da Saúde, Centro Universitário de Brasília, Brasília, DF, Brasil.

Silveira, A. (2010). Produção científica em empreendedorismo feminino: análise dos periódicos indexados no Social Sciences Citation Index. In F. A. Gimenez, J. M. Ferreira, \& S. C. Ramos (Orgs.), Empreendedorismo e estratégia de empresas de pequeno porte - 3Es2Ps (Vol.1, pp. 71-87). Curitiba: Editora Champagnat.

Stangherlim, R. (2006). Sentidos subjetivos na relação professor-aluno. Revista de Educação AEC, $35(139), 51-59$.

Vygotski, L. S. (2009). A construção do pensamento e da linguagem (2a ed., P. Bezerra, Trad.). São Paulo: WMF Martins Fontes. (Obra original publicada em 1934)

Zampier, M. A., Takahashi, A. R., \& Teixeira, R. M. (2010). Intraempreendedorismo feminino e desenvolvimento de competências empreendedoras: um estudo de caso com professoras de programas de mestrado e doutorado em Administração de Curitiba-PR. Anais do Encontro de Estudos Sobre Empreendedorismo e Gestão se Pequenas Empresas, Londrina, PR, Brasil, 6. 